\title{
Information and Subsidies: Complements or Substitutes?
}

\section{Citation}

Ashraf, Nava, B. Kelsey Jack, and Emir Kamenica. "Information and Subsidies: Complements or Substitutes?" Journal of Economic Behavior \& Organization 88 (April 2013): 133-139.

\section{Published Version}

DOI: 10.1016/j.jebo.2012.12.031;http://www.sciencedirect.com/science/article/pii/

S0167268112003034

\section{Permanent link}

http://nrs.harvard.edu/urn-3:HUL.InstRepos:13348079

\section{Terms of Use}

This article was downloaded from Harvard University's DASH repository, and is made available under the terms and conditions applicable to Open Access Policy Articles, as set forth at http:// nrs.harvard.edu/urn-3:HUL.InstRepos:dash.current.terms-of-use\#OAP

\section{Share Your Story}

The Harvard community has made this article openly available.

Please share how this access benefits you. Submit a story.

Accessibility 


\title{
Information and Subsidies: Complements or Substitutes?
}

\author{
Nava Ashraf \\ B. Kelsey Jack \\ Harvard Business School ${ }^{\mathrm{a}}$ \\ Tufts University ${ }^{\mathrm{b}}$ \\ Emir Kamenica \\ University of Chicago Booth School of Business ${ }^{\mathrm{c}}$ \\ January 2, 2013
}

\begin{abstract}
Does providing information about a product influence the impact of price subsidies on purchases? This question is particularly relevant for health products in developing countries where both informational campaigns and price subsidies are common policy instruments. We conduct a field experiment in Zambia and find that providing information about a new version of a product significantly increases the impact of price subsidies on take-up. Taken alone, the information manipulation has no significant impact on demand while the price subsidy substantially increases demand. However, the evaluation of either intervention in isolation fails to capture the significant complementarity between the two.
\end{abstract}

Keywords: subsidies; information; health JEL Codes: D83, H23, I18, O12

\footnotetext{
${ }^{a}$ Email: nashraf@hbs.edu

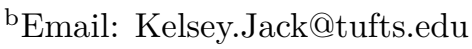

cEmail: Emir.Kamenica@chicagobooth.edu
} 


\section{Introduction}

Governments and NGOs commonly use both informational campaigns and price subsidies in attempts to increase the use of health products and other socially beneficial technologies in developing countries (Hecht and Shah 2006, Nugent and Knaul 2006). The optimal deployment of these policy instruments depends on the way they interact in the policy maker's production function; if providing households with information about a product changes the demand function, it may also affect the policy maker's optimal level of a price subsidy.

Information about a product can impact demand in two broad ways. First, providing information can affect the overall level of demand. For instance, information can increase demand by allowing consumers to purchase more appropriate products (Tadelis and Zettelmeyer 2011). Or, if the quality of the product does not match consumers' ex ante expectations, providing information can change the average perception of quality (Caswell and Mojduszka 1996). Second, and more important for our purposes, providing information can change the elasticity of demand (and thus the impact of price subsidies). For example, information can increase the dispersion of consumers' valuation, which rotates the demand curve clockwise, making demand less sensitive to price (Johnson and Myatt 2006). But, if consumers' initial beliefs are more heterogeneous than their valuations, information will have the exact opposite effect. Moreover, information can reduce the extent of consumers' price-based inference, thus making demand more sensitive to price (Judd and Riordan 1994). ${ }^{1}$ Hence, the impact of information on the level and the slope of the demand curve is fundamentally an empirical question.

In this paper, we estimate the causal impact of information about an unfamiliar health product on the effectiveness of price subsidies. Using door-to-door marketing in Lusaka, Zambia, we offered a new, unfamiliar water purification product for sale to 487 households, randomly varying both the price subsidy and the information about the product. We offered this unfamiliar target product alongside a familiar substitute

\footnotetext{
${ }^{1}$ Wedig and Tai-Seale (2002) show that giving consumers a report card with detailed information about the quality and coverage of health insurance plans increases the elasticity of demand with respect to price.
} 
product (Clorin), which we sold at its regular market price of 800 Zambian Kwacha (around $0.20 \mathrm{USD}){ }^{2}$ We varied the price of the target product from zero (full subsidy) to 1200 Kwacha (no subsidy). ${ }^{3}$ This variation allows us to estimate the quantity demanded across the full range of relevant subsidy levels. We varied the information through a simple manipulation that involved telling some subjects that the target product is "an alternative water purification solution that is not available for purchase in Zambia but that we are offering this month only for sale to randomly selected households in your area." Other subjects were told on addition that "the solution contains the same ingredients as regular Clorin but the strength or concentration of the ingredient is higher" and were given the opportunity to inspect the product. ${ }^{4}$ We refer to these two groups of households as uninformed and informed, respectively. ${ }^{5}$

Our main specification compares the impact of the price subsidy on purchase behavior across uninformed and informed households. Overall, 34 percent of households purchase the target product. The probability that an uninformed household purchases the product increases by 3.4 percentage points for every 100 Kwacha increase in the price subsidy. Among the informed households, this effect is 5.4 percentage points. In other words, information and subsidies are complements: providing consumers with additional information about the product increases the effectiveness of price subsidies by about 60 percent. Our result is driven by consumers' shift from the familiar product toward the target one, not by an overall increase in the demand for water purification.

While our data do not pin down a specific mechanism behind the observed complementarity, one straightforward way to interpret our results is through price signaling. In the absence of information, people tend to take a price of the unfamiliar product

\footnotetext{
${ }^{2}$ In 2004, the average monthly income for a household in a low income urban neighborhood in Zambia was 645,000 Kwacha (Central Statistics Office 2005).

${ }^{3}$ The unfamiliar product is not available for sale in Zambia, but based on estimated costs of production and distribution, its market price under perfect competition would be around 1200 Kwacha.

${ }^{4}$ The English language script is in the Appendix. Scripts were administered in Nyanja.

${ }^{5}$ Our information manipulation relies on the presence of the familiar substitute product to convey quality information. In this way, it is most similar to information campaigns that offer explicit product comparisons or demonstrates the mechanisms through which a product works. In our sample, over 90 percent of respondents report having used Clorin in the past.
} 
as a signal of its quality, so high prices do not diminish the quantity demanded very much. When information is provided, the signaling content of the price diminishes. As a result, demand becomes more elastic. ${ }^{6}$ In particular, informed consumers see no reason to pay more for the new product given that it has the same ingredients as the familiar one. The effect of the information is thus to encourage more people to switch from the substitute product to the target one at low prices, and vice versa at high prices.

As in many other field experiments, our ability to generalize beyond the specific product, context, and intervention is limited. In particular, one could certainly imagine circumstances where price signaling is unlikely to be important. Despite the limited generalizability, however, our paper makes two substantive contributions.

First, we find that the complementarity between two commonly used policy instruments, subsidies and information, can be quite large; in our setting, the impact of price subsidies is 60 percent greater among the informed households. The magnitude of this point estimate highlights the potential importance of taking complementarities into account when designing policy interventions. Second, previous work on pricing of health products in developing countries (Dupas 2009, Ashraf et al. 2010, Cohen and Dupas 2010) has focused almost exclusively on products that are familiar. Our study reveals that optimal pricing may be different for products that are new or unfamiliar.

The paper proceeds as follows. The next section relates our result to the existing literature. The following describes the design and the implementation of the field experiment. Section 4 presents the empirical results. Section 5 concludes.

\section{Existing literature}

Our paper primarily relates to two strands of existing literature. Numerous studies have estimated the impact of information programs (Jalan and Somanathan 2008, Luoto et al. 2012) and price subsidies (Kremer and Miguel 2007, Ashraf et al. 2010,

\footnotetext{
${ }^{6}$ Judd and Riordan (1994) present a model that formalizes this idea.
} 
Cohen and Dupas 2010) in isolation. Our paper is more closely related to the small literature that examines interactions between the two policies. ${ }^{7}$ Dupas (2009) compares purchase decisions at various levels of subsidies for insecticide treated mosquito nets, with information treatments that alternatively stress the health or financial benefits of malaria prevention. ${ }^{8}$ She finds that neither information treatment affects the demand function. Dupas (2012) considers a setting with endogenous information acquisition and finds that short-run subsidies for insecticide treated nets can increase long-run demand. Duflo et al. (2012) examine the interaction between HIV information and education subsidies (free school uniforms) on early pregnancy and sexually transmitted infections (STIs) among teenage girls in Kenya. They find that education subsidies have a stronger effect on STIs when accompanied by information, but a weaker effect on early fertility when information is provided than when it is not. Finally, Meredith et al. (2012) vary the provision of health information at different subsidy levels for a variety health products in four countries. In only one of their seven experiments do subsidies have a differential effect on demand when coupled with information. In contrast to our experiment, none of aforementioned studies analyze the potential complementarity between subsidies and information about the specific product that is being subsidized.

Our paper is also related to a literature outside of development on the interaction between prices and advertising by profit-maximizing firms. Early work by Prasad and Ring (1976) documents greater price sensitivity among consumers exposed to greater amounts of advertising. ${ }^{9}$ More recent work by Kaul and Wittink (1995) surveys

\footnotetext{
${ }^{7}$ Some work also examines potential complementarities between other interventions. Cole et al. (2011) find no complementarity between financial literacy training and subsidies in their impact on the demand for credit. Gine and Mansuri (2011) show that business training is no more effective when coupled with access to credit. Groh et al. (2012) find that employability skills training does not increase the impact of a wage subsidy program. Doi et al. (2012) document that financial literacy training has a much greater impact on saving when provided both to the migrant worker and to their family in the home country.

${ }^{8}$ Berry et al. (2012) examine an interaction between price subsidies and provision of information about the market price of the product. They find that the impact of subsidies is not affected by the provision of this information.

${ }^{9}$ Our experiment is also connected to the marketing literature on the preference for well-known brands (for example, Hoyer and Brown 1990 show that consumers use brand as a choice heuristic).
} 
marketing research on the effect of advertising on price sensitivity and concludes that non-price advertising tends to decrease price sensitivity, though evidence is mixed. Our suggested channel of price signaling has been extensively explored in economic theory (e.g., Milgrom and Roberts 1986), though empirical evidence on the topic is scant (Heffetz and Shayo 2009).

\section{Experimental design}

Our experimental design is straightforward. We varied both how much information we provide to consumers and how much we subsidize the product we are asking them to buy. These two orthogonal sources of variation allow us to assess the complementarity between information and subsidies.

To increase the chance that our informational intervention has an impact, we used an unfamiliar good as our target product. Specifically, we imported two varieties of water purification products: AquaGuard and WaterGuard from Uganda and Kenya respectively. Initially, these were intended to represent branded (Uganda) versus unbranded (Kenya) products to assess the potential interaction of treatment effects with branding. However, the two imported products were identical in the size and shape of their bottles and focus groups gave mixed responses as to which looked more "branded". Accordingly, the two unfamiliar products, which were balanced across treatments, are pooled throughout the analysis. ${ }^{10}$ For the remainder of the paper we refer to both AquaGuard and WaterGuard as the target product.

Our experiment was implemented in collaboration with Society for Family Health ( $\mathrm{SFH}$ ). SFH is a social marketing firm that sells Clorin, the commonly used water purification system, in Zambia. SFH is a non-profit organization that distributes Clorin through door-to-door marketing and aims to set prices to maximize take-up and use rather than profits. ${ }^{11}$

\footnotetext{
${ }^{10}$ Our results are unchanged if we include a control for the type of the unfamiliar product in Equation (2).

${ }^{11} \mathrm{SFH}$ is well known in the neighborhoods where we conducted the study. We also administered a small survey to 41 respondents and asked about their perceptions of SFH. Respondents were asked whether SFH was a good, bad or okay organization and whether its products were of high, low
} 
While the basic logic of our design could have been implemented by simply offering the target product for sale, based on discussions with SFH we also offered Clorin for sale at its standard (subsidized) market price alongside the target product. One benefit of doing so was to make the households' interaction with the marketers less unusual by presenting, alongside the target product, a familiar product at a familiar price. Like most subsidized health products in Lusaka, and elsewhere in the developing world, Clorin is sold at a posted price with no reference to its subsidization. Consequently, to maximize external validity, we did not tell our subjects that the target product we offered them is subsidized. The details of our design are as follows.

A team of 6 marketers worked in 6 low-to-middle income compounds in Lusaka over a period of approximately 4 weeks in August and September of 2007. Lack of street addresses and detailed maps made ex ante random sampling infeasible, so marketers were instructed to visit every fifth house along a street. If no one was home in the target house, they visited the house to the right, and if that also failed, then the house to the left, before counting another 5 houses along the street. Marketers traveled in groups of two to a different compound each day.

The marketing scripts were designed to make the interaction similar to other door-to-door marketing campaigns in Lusaka. Scripts were pre-printed to reflect the 26 conditions: informed vs. uninformed crossed with 13 different subsidy levels from K0 $($ price $=\mathrm{K} 1200)$ to K1200 (price $=$ zero) in K100 increments. ${ }^{12}$ Scripts were provided to marketers in random order and they were instructed to use them in that order. Checks of ordering according to position along selected streets confirmed that the randomization was followed. Either 18 and 19 observations were collected in each condition for a total of 487 observations. ${ }^{13}$

In all treatments, a single female marketer approached the house, introduced

or okay quality. Seventy-nine percent indicated that SFH was a good organization and 43 percent thought its products were of high quality.

${ }^{12}$ The price was not framed as a subsidy to the consumer, in keeping with the NGO's typical approach.

${ }^{13}$ One treatment combination (informed, subsidy of K900) contains only 17 observations due to a failure of a single marketer to meet her target on the final day of data collection. Marketers were paid by the day, and were given performance targets associated with number of households visited. Pay was not tied to sales of either the target product or Clorin. 
herself as being a representative of SFH and asked to speak with the female head of household. If the female head was not present, the visit was terminated, and the marketer continued to the next house in the sampling scheme. If the female head was available, the marketer explained that she was selling water purification solutions.

All subjects were told that two types of purification solutions were available and only a single bottle could be purchased of either Clorin at the standard price of K800, or the target product at K[randomly determined price]. The two products were displayed in a transparent plastic case. All subjects were told that the target product is sold in other countries but is not available for purchase in Zambia except for randomly selected households in the area for a short time. In the informed treatment, the marketer opened the display case and removed both bottles for the respondent to inspect. In addition, the informed subjects were given detailed information about the similarity between the target product and Clorin, including the fact that the two products have the same active ingredient and same treatment instructions. The target product had a slightly higher concentration so the bottle was slightly smaller to offer the same treatment capabilities.

After hearing the information about the products, subjects were asked whether they would like to purchase either a bottle of Clorin or a bottle of the target product. The marketers made it clear that the household could purchase at most one bottle of at most one product. After subjects completed their purchase decisions, marketers asked a brief set of survey questions. In addition, the marketers recorded any freeform comments and were trained on a set of pre-scripted responses to frequently asked questions.

Some aspects of our experimental design might appear contrived. However, doorto-door marketing is very common in Lusaka, particularly in the low-to-middle income compounds where the study was implemented. Among health products, perfect or near complements are often found on the market in Zambia, such as generic and branded condoms, or water purification tablets and solution. Both consumer information and subsidy levels differ across the alternatives. Moreover, products are often brought to Zambia from other countries for short-term off-loads of production surpluses. An informal survey identified many products that were available only for 
short periods of time in Lusaka in the past, including cooking pots from South Africa, cosmetics from the United Kingdom and candy from the United States. Accordingly, we think it plausible that most of the households in our sample did not suspect that they were a part of an experiment, except perhaps those who were offered the target product for free. ${ }^{14}$ Excluding those subjects from our analyses only strengthens our findings.

\section{Results}

\subsection{Separate impact of information and subsidies}

While our main focus will be on the interaction between information provision and price subsidies, we begin our analysis by examining the independent impact of each of these interventions. Table 1 fully describes all the choice data from our experiment. The Table reports the number of households that purchase Clorin and the number of households that purchase the target product in each of the 26 conditions. Figure 1 plots the share of subjects purchasing the target product in each subsidy-information treatment cell. Throughout the paper we will focus on purchase of the target product as the outcome variable.

As we discussed earlier, providing information can either increase or decrease demand. Information allows consumers to select more appropriate products and to use them more appropriately; this force can lead information to increase demand. On the other hand, consumers' initial beliefs about quality might be optimistic, which could lead information to decrease demand. Pooling over all subsidy levels, 32\% of the uninformed households purchase the target product; providing information increases that fraction to $37 \%$. This difference, however, is not statistically significant $(p=0.252)$.

Pooling across the two information conditions, we examine the impact of subsidies

\footnotetext{
${ }^{14}$ Oral consent was obtained before we administered the survey after the purchase decision. The project was exempted from review by the Harvard Business School Institutional Review Board because we did not collect identifiers and implemented the project within the ongoing activities of $\mathrm{SFH}$.
} 
on purchases by considering a linear probability model:

$$
\operatorname{Purchase}_{i}=\alpha+\beta_{S} \times \operatorname{Subsidy}_{i}+\varepsilon_{i}
$$

where $i$ indexes households, Purchase $i$ is an indicator variable for whether the head of household purchased the target product, and Subsidy $_{i} \in\{0,1, \ldots, 12\}$ is the extent of the price subsidy, in units of K100. Column (2) of Table 2 reports the regression estimates with heteroskedasticity robust standard errors. Each additional K100 subsidy increases probability of purchase by 4.4 percentage points $\left(\hat{\beta}_{S}=0.044\right)$. This effect of subsidy on purchases is highly significant $(p<0.01)$.

\subsection{Complementarity of information and subsidies}

In this subsection we turn to our main question: are information and price subsidies complements or substitutes? As before, we utilize a linear probability model, but using a logit or a probit instead yields similar results. Our main regression is:

$$
\begin{aligned}
\text { Purchase }_{i} & =\alpha+\beta_{S} \times \text { Subsidy }_{i}+\beta_{I} \times \text { Information }_{i} \\
& +\beta_{C} \times \text { Subsidy }_{i} \times \text { Information }_{i}+\varepsilon_{i}
\end{aligned}
$$

where Information $_{i}$ is an indicator variable for whether the household was informed and other variables are defined as earlier. Column (3) of Table 2 reports the estimates. For households given no subsidy, the informational intervention is estimated to decrease purchases by 7 percentage points $\left(\hat{\beta}_{I}=-0.070\right)$, though this effect is not significant. ${ }^{15}$ Among the uninformed households, the probability of purchase increases by 3.4 percentage points for each additional K100 in subsidies $\left(\hat{\beta}_{S}=0.034\right)$. In contrast, among the informed households, each additional K100 in subsidies in-

\footnotetext{
${ }^{15}$ Recall that information we provided to informed households suggested that the target product was very similar to Clorin. Hence, it is not surprising that for households who were offered no subsidies on the target product, i.e., for whom the target product was $50 \%$ more expensive than Clorin, providing this information made Clorin seem more attractive than the target product.
} 
creases purchases by 5.4 percentage points $\left(\hat{\beta}_{S}+\hat{\beta}_{C}=0.054\right)$. In other words, providing consumers with information increases the effectiveness of price subsidies by $60 \%$. This effect is marginally significant, just shy of the conventional $5 \%$ level $(p=0.055)$. These results are robust to the inclusion of compound and marketer fixed effects. ${ }^{16}$

We also examine to what extent information and subsidies affect the purchases of the target product through substitution from Clorin. Column (4) of Table 2 reports the results of a regression where the dependent variable is whether the household purchased either the target product or Clorin. The coefficient on Subsidy $_{i} \times$ Information $_{i}$ is close to zero, ${ }^{17}$ which suggests that information makes price subsidies more effective in inducing households to substitute Clorin for the target product, rather than in inducing households to purchase a water purification system. This may be due to the fact that the information we provided was primarily about the merits of the target product relative to Clorin rather than about water purification systems or the health risks of untreated water in general. ${ }^{18}$

\section{Discussion}

We present simple evidence on the interaction between two interventions designed to increase demand for an unfamiliar health product. We find that the marginal impact of a price subsidy is greater if consumers are also given information about the product. This result indicates that precise product information and subsidies can be complements in the NGO's production function and that program evaluation and intervention design can be improved by considering interactions across demand generation strategies.

\footnotetext{
${ }^{16}$ Compound fixed effects tighten the standard errors without changing the magnitude of $\hat{\beta}_{C}$, increasing the significance slightly to $p=0.049$. Marketer fixed effects increase standard errors slightly $(p=0.082)$, again without changing the magnitude of $\hat{\beta}_{C}$. Finally, including both compound and marketer fixed effects results in $p=0.072$.

${ }^{17}$ We can reject the hypothesis that this coefficient is the same as in column (3).

${ }^{18}$ Ideally, we would also wish to know whether purchases of the target product had any long-term impact on the use of water purification products, but obtaining such data was not feasible.
} 
While our design is simple, it controls for many of the complexities associated with the introduction of new health products in developing countries, such as repeated purchases (Dupas 2010), learning from own experience and the experience of others (Oster and Thornton 2012), and expectations of future prices (Berry et al. 2012). Some of our design features, however, come at a cost. For instance, we intentionally give subjects a one-shot decision to avoid inter-temporal substitution and endogenous information acquisition. Yet, the decision to take up a new health product is typically a dynamic one, and our design ignores the nuances of repeated purchase opportunities and information dissemination. In this sense, our findings complement Dupas' (2012) two-stage design in which random variation in prices in the first period is followed by endogenous learning and a second purchase opportunity. Her results show a positive relationship between price subsidies and endogenous information dissemination, while we show a positive interaction between price subsidies and exogenously provided information. By constraining the purchase decision to a one-time purchase of at most one unit of the product, our results are most informative about the factors that drive consumers to try new or unfamiliar products.

While we remain agnostic about the specific mechanism that drives our results, our findings are consistent with consumers making inferences about product quality from product price. In many models of this phenomenon (e.g., Judd and Riordan 1994), consumers' inference makes demand less sensitive to price since lower prices signal lower quality. Hence, providing consumers with product information reduces the role of inference, thus makes the demand function steeper, and in turn makes price subsidies more effective.

Our ancillary data provide some support for this interpretation of the results. In the survey conducted after the purchase decision we find that the perceived quality of the target product relative to Clorin is negatively related to the subsidy level. Moreover, informed subjects' perception of quality is less affected by the subsidies, though this interaction effect is both economically small and statistically insignificant. Finally, the free-form comments from the subjects also support a role of inference. These comments include statements that "free one can't be good," "it's better that's 
why it's expensive," and "how you tell if something is better is by the price."

Whatever the mechanism behind our results may be, the complementarity between information and subsidies implies they will more effective when applied in unison. Identifying the contexts in which subsidies and information act as complements will help build on these initial results, as will further experimentation to isolate the channels through which subsidies and production information interact. 


\section{Acknowledgements}

The authors would like to acknowledge Jesse Shapiro's generous contributions to the development of this paper. Comments on earlier drafts were provided by Chris Avery, Pascaline Dupas, Ed Glaeser, Guido Imbens, Dean Karlan, Asim Khwaja, Tristan Zajonc and workshop participants at Harvard. Society for Family Health in Lusaka, Zambia facilitated the implementation of the experiment. Special thanks are due to Esnea Mlewa and Richard Harrison. 


\section{References}

[1] Andreasen, A. R., 2002. "Marketing Social Marketing in the Social Change Marketplace." Journal of Public Policy \& Marketing, 21(1):3-13.

[2] Ashraf, N., J. Berry and J. Shapiro, 2010. "Can Higher Prices Stimulate Product Use? Evidence from a Field Experiment in Zambia." American Economic Review, 100(5):2383-2413.

[3] Berry, J., G. Fischer and R. Guiteras, 2012. "Eliciting and Utilizing Willingness to Pay: Evidence from Field Trials in Northern Ghana." Mimeo.

[4] Caswell, J. A. and E. M. Mojduszka, 1996. "Using Informational Labeling to Influence the Market for Quality in Food Products." American Journal of Agricultural Economics, 78(5):1248-1253.

[5] Central Statistics Office of Zambia, 2005. "Living Conditions Monitoring Survey Report." Government of Zambia.

[6] Cohen, J. and P. Dupas, 2010. "Free Distribution or Cost-Sharing? Evidence from a Randomized Malaria Prevention Experiment." The Quarterly Journal of Economics, 125(1):1-45.

[7] Cole, S., T. Sampson and B. Zia, 2011. "Prices or Knowledge? What Drives Demand for Financial Services in Emerging Markets?" The Journal of Finance, 66(6):1933-1967.

[8] Doi, Y., D. McKenzie and B. Zia, 2012. "Who You Train Matters: Identifying Complementary Effects of Financial Education on Migrant Households." Mimeo.

[9] Duflo, E., P. Dupas and M. Kremer, 2012. "Education, HIV and Early Fertility: Experimental Evidence from Kenya." Mimeo. 
[10] Dupas, P., 2009. "What Matters (and What Does Not) in Households' Decision to Invest in Malaria Prevention?" American Economic Review: Papers and Proceedings, 99(2): 224-230.

[11] Dupas, P., 2012. "Short-run Subsidies and Long-term Adoption of New Health Products: Evidence from a Field Experiment." Mimeo.

[12] Gine, X. and G. Mansuri, 2011. "Money or Ideas? A Field Experiment on Constraints to Entrepreneurship in Rural Pakistan." Mimeo.

[13] Groh, M., N. Krishnan, D. McKenzie and T. Vishwanath, 2012. "Soft Skills or Hard Cash? The Impact of Training and Wage Subsidy Programs on Female Youth Employment in Jordan." Mimeo.

[14] Hastings, G., 2007. Social marketing: Why should the Devil have all the best tunes? Maryland Heights: Butterworth-Heinemann.

[15] Hecht, R. and R. Shah, 2006. "Disease Control Priorities in Developing Countries." In Recent Trends and Innovations in Development Assistance for Health. World Bank.

[16] Heffetz, O. and M. Shayo, 2009. "How Large Are Non-BudgetConstraint Effects of Prices on Demand." American Economics Journal: Applied Economics, 1(4):170-199.

[17] Hoyer, W. and S. Brown, 1990. "Effects of Brand Awareness on Choice for a Common, Repeat-Purchase Product." Journal of Consumer Research. 17(2):141-148.

[18] Jalan, J. and E. Somanathan, 2008. "The Importance of Being Informed: Experimental Evidence on Demand for Environmental Quality." Journal of Development Economics, 87(1):14-28.

[19] Johnson, J. P. and D. P. Myatt, 2006. "On the Simple Economics of Advertising, Marketing, and Product Design." American Economic Review, 96(3):756-784. 
[20] Judd, K. L. and M. H. Riordan, 1994. "Price and Quality in a New Product Monopoly." The Review of Economic Studies, 61(4):773-789.

[21] Kaul, A. and D. R. Wittink, 1995. "Empirical Generalizations About the Impact of Advertising on Price Sensitivity and Price." Marketing Science, 14(3):151-160.

[22] Kremer, M. and E. Miguel, 2007. "The Illusion of Sustainability." The Quarterly Journal of Economics, 122(3):1007-1065.

[23] Lewis, T. R. and D. E. M. Sappington, 1994. "Supplying Information to Facilitate Price Discrimination." International Economic Review. 35(2):309-327.

[24] Luoto, J., D. Levine and J. Albert, 2012. Information and Persuasion: Achieving Safe Water Behaviors in Kenya." Mimeo.

[25] Meredith, J., J. Robinson, S. Walker and B. Wydick, 2012. "Keeping the Doctor Away: Experimental Evidence on Investment in Preventative Health Products." Mimeo.

[26] Milgrom, P. and J. Roberts, 1986., "Price and Advertising Signals of Product Quality." Journal of Political Economy, 94(4):796-821.

[27] Nugent, R. and F. Knaul, 2006. Fiscal Policies for Health Promotion and Disease Prevention. In Disease Control Priorities in Developing Countries. Jamison, D. T., J. G. Breman, A. R. Measham, et al. Washington (DC): World Bank.

[28] Oster, E. and R. Thornton, 2012. "Determinants of Technology Adoption: Private Value and Peer Effects in Menstrual Cup Take-Up." Journal of the European Economic Association.

[29] Prasad, V. K. and L. W. Ring, 1976. "Measuring Sales Effects of Some Marketing Mix Variables and Their Interactions." Journal of Marketing Research, 13(4):391-396. 
[30] Tadelis, S. and F. Zettelmeyer, 2011. "Information Disclosure as a Matching Mechanism: Theory and Evidence from a Field Experiment." Mimeo.

[31] Wedig, G. J. and M. Tai-Seale, 2002. "The Effect of Report Cards on Consumer Choice in the Health Insurance Market." Journal of Health Economics. 21(6):1031-1048 


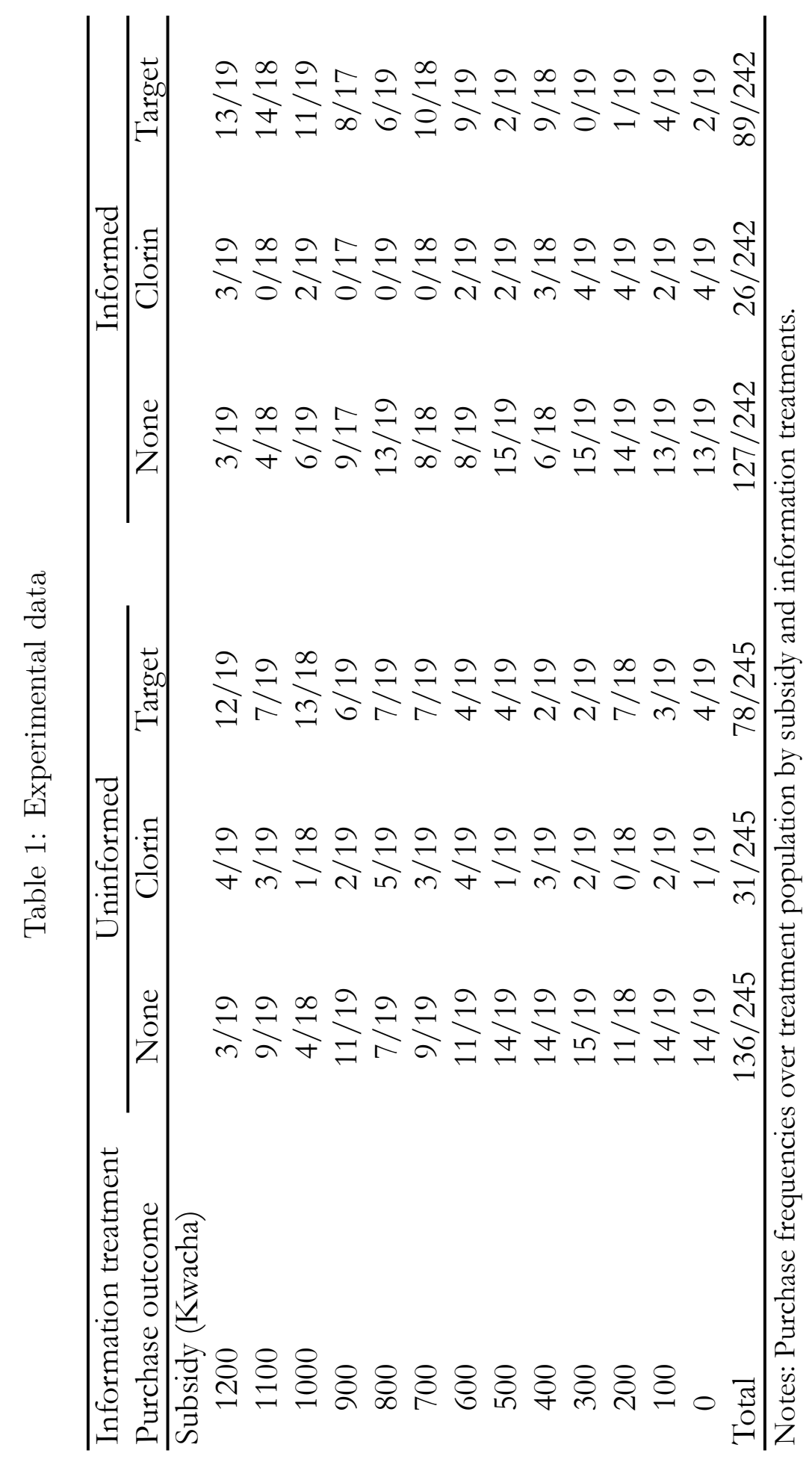


Table 2: Impact of subsidy on purchase probabilities

\begin{tabular}{lcccc}
\hline Dependent variable & \multicolumn{3}{c}{ Purchase target product } & $\begin{array}{c}\text { Purchase either } \\
\text { product }\end{array}$ \\
& $(1)$ & $(2)$ & $(3)$ & $(4)$ \\
\hline Subsidy & & 0.044 & 0.034 & 0.044 \\
& & $(0.005)$ & $(0.008)$ & $(0.008)$ \\
Information & 0.049 & & -0.070 & 0.044 \\
Subsidy * Information & $(0.043)$ & & $(0.068)$ & $(0.079)$ \\
& & & 0.020 & -0.002 \\
Constant & 0.318 & 0.078 & $(0.011)$ & $(0.011)$ \\
& $(0.030)$ & $(0.038)$ & 0.113 & 0.182 \\
R-squared & 0.001 & 0.120 & $0.054)$ & $(0.055)$ \\
N & 487 & 487 & 487 & 0.099 \\
Mean of Dependant Variable & 0.343 & 0.343 & 0.343 & 487 \\
\hline
\end{tabular}

Notes: All outcomes are binary and estimates are from linear probability models. Heteroskedasticity-robust standard errors in parentheses. Subsidies are in K100. Columns 1-3 use a binary dependent variable equal to one if the subject purchases the target product. Column 4 uses a binary dependent variable equal to one if the subject purchases either product (target product or Clorin). 
Figure 1: Effect of subsidy on purchases of the target product

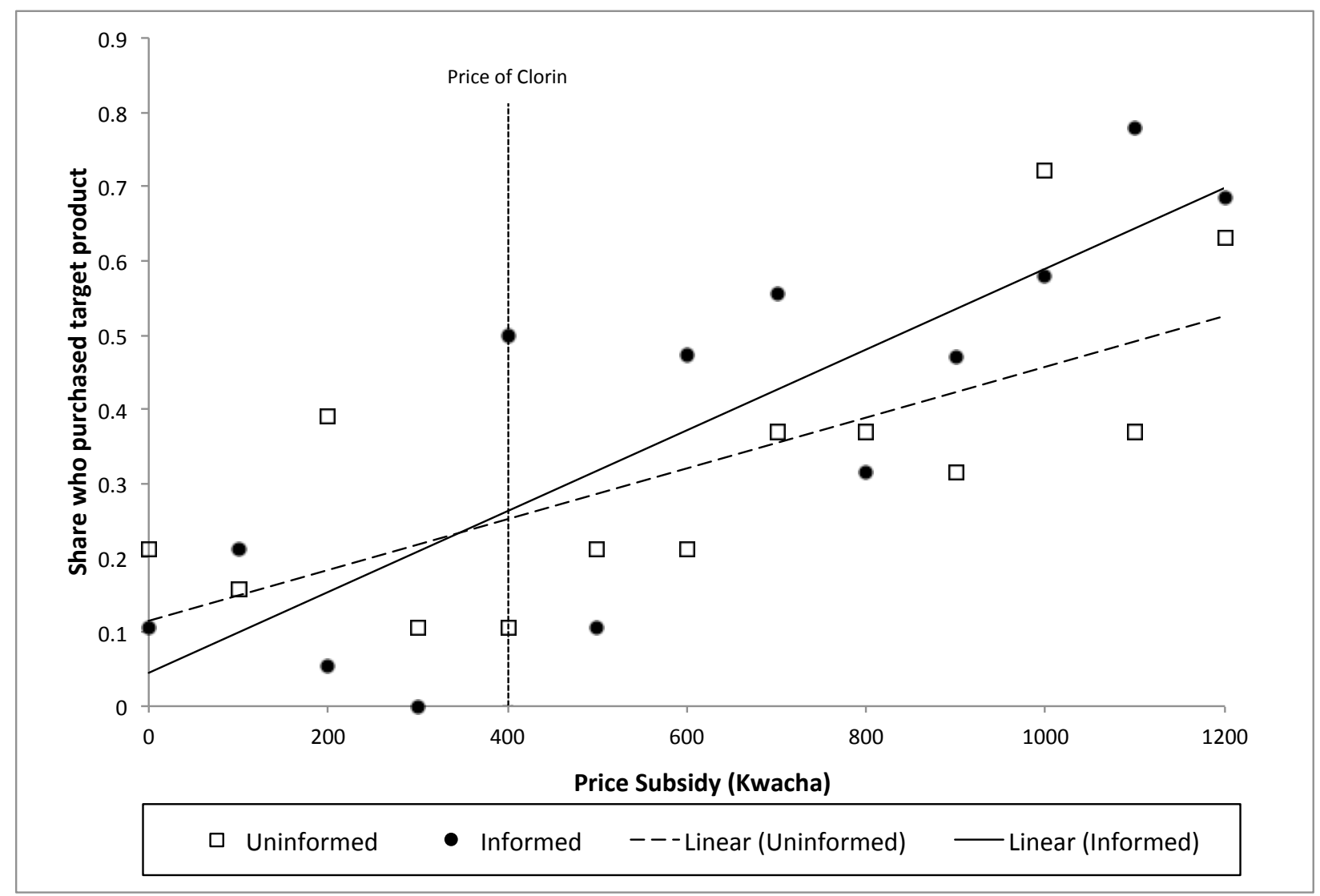

Notes: The figure plots the share of subjects who purchase the target product at each subsidy level, and the linear fit line for the informed and uninformed experimental treatments. 


\section{Appendix: Marketing script}

\author{
Marketer: \\ Date: \\ Alt Product: WG AG
}

\author{
House plot no: \\ Compound: \\ Nearby landmark:
}

STEP 1 Hello and how are you? My name is representing the Society for Family Health. and I am

STEP 2 'Is the female head of the household here?'

Yes it's me/ Yes let me go get her. ( $\rightarrow$ Go to STEP 3 )

No she is not here. ( $\rightarrow$ Go to STEP 9)

STEP 3 We are going today to randomly selected households in your area, in order to make water purification solutions available for sale from SFH.

As you may know, Clorin is a water purification treatment, usually sold in retailers at around $800 \mathrm{Kw}$ per bottle. Today we would like to offer to sell you a single bottle of water purification solution. We have two types of water purification solution available.

INFO TREATMENT ONLY: I would like to tell you a few things about the alternative water purification solution. The solution contains the same ingredients as regular Clorin but the strength or concentration of the ingredient is higher. As you can see, the bottle is smaller than the regular Clorin bottle. The way that the alternative product kills germs is the same as regular Clorin, and it will have the same effect on the taste of the water.

[REMOVE BOTTLES FROM DISPLAY AND SHOW CUSTOMER INFORMATION ON BOTH BOTTLES: concentration, volume, use instructions]

The lid measurements are designed for the same size water containers as the regular Clorin bottle (20 liters), but since it is stronger, you should follow the measurement instructions on the bottle. The way you treat water with the alternative water purification solution is the same as regular Clorin. Mix, shake and wait for 30 minutes.

The first for sale is the regular Clorin you are accustomed to seeing in stores. We can offer that to you for $800 \mathrm{KW}$. The second is an alternative water purification solution that is not available for purchase in Zambia but that we are offering this month only for sale to randomly selected households in your area. The product will not be available after this short term sale period. It is available for sale in other countries all the time. We can offer that to you for PRICE Kw.

STEP 4 Would you be interested in purchasing one of these two bottles of water purification solution today?

Yes $(\rightarrow$ Go to STEP 5 ) No ( $\rightarrow$ Go to STEP 7)

Reason for no purchase, if volunteered (do not prompt):

STEP 5 Would you like to buy the Clorin for K800 or the alternative water purification solution for KPRICE?

Clorin

Alternative

STEP 6 Wonderful. If you wouldn't mind, could you sign this receipt for my supervisor? [Complete receipt and have recipient sign.]

$\rightarrow$ Go to Questions 